\title{
EXPERIMENTAL INVESTIGATION OF PERFORMANCE AND COMBUSTION CHARACTERISTICS ON A SINGLE CYLINDER LHR ENGINE USING DIESEL AND CASTOR BIODIESEL
}

\author{
Ravasab S Kumbar ${ }^{1}$, Prakash S Patil ${ }^{2}$, Omprakash Hebbal ${ }^{3}$ \\ ${ }^{I} P G$ Student, Thermal Power Engineering PDACE Gulbarga, Karnataka, India \\ ${ }^{2}$ Associate professor, ${ }^{3}$ Professor, Dept of Mechanical Engineering PDACE Gulbarga, Karnataka, India
}

\begin{abstract}
In this present investigation castor biodiesel a non edible vegetable oil is selected as a alternative fuel to analyze the performance and combustion characteristics with and without modification of diesel engine. A castor oil is converted in to castor biodiesel by transesterification process and blended with diesel in 25/75\%, 50/50\%, 75/25\% and 100\% on volume basis and analyzed and compared with diesel. The performance and combustion characteristics of blends are evaluated at variable loads of 0, 1,2,3,4,5.2 at rated speed of $1500 \mathrm{rpm}$ and results are compared with diesel. The thermal efficiency, bsfc, mechanical efficiency, volumetric efficiency are well comparable with diesel for diesel engine and LHR engine and better performance and combustion characteristics are observed in case of Low Heat Rejection engine. From investigation it can be stated that up to 25\% blend of castor biodiesel can be substituted for diesel engine without any modification. And with modification we can blend up to $25 \%$ but we can get better performance and combustion characteristics than normal engine.
\end{abstract}

Keywords: Castor biodiesel, low heat rejection engine, COME.

\section{INTRODUCTION}

The most harmful effect of our present day civilization is global warming and environmental pollution. With rapid industrialization and urbanization we are also making our planet unsafe for us and for the generations to come. The vehicle population throughout the world is increasing rapidly; in India the growth rate of automotive industry is one of the largest in the world. It is quite evident that the problem cannot be solved with the conventional fossil fuels, however stringent the emission control norms may be. The consumption of diesel fuels in India was 28.30 million tones which was $43.2 \%$ of the consumption of petroleum products. This requirement was met by importing crude petroleum as well as petroleum products. The import bill on these items was 17,838 crores. With the expected growth rate of diesel consumption of more than $14 \%$ per annum, shrinking crude oil reserves and limited refining capacity, India will be heavily dependent on imports of crude petroleum and petroleum products.

The drawbacks associated with vegetable oils and biodiesels for use in diesel engines call for LHR engines. It is well known fact that about $30 \%$ of the energy supplied is lost through the coolant and the $30 \%$ is wasted through friction and other losses, thus leaving only $30 \%$ of energy utilization for useful purposes. In view of the above, the major thrust in engine research during the last one or two decades has been on development of LHR engines The study also focuses on coating method for Plasma Spray aluminum oxide to improve coating under high load and temperature cyclical conditions encountered in the real engine. The effect of insulation on engine performance, heat transfer characteristics, combustion and emission characteristics are studied and compared with standard (STD) diesel engine

\section{THE PROPERTIES OF DIESEL FUEL AND} COME

The different properties of diesel fuel and COME are determined and given in below table1. After transesterification process the fuel properties like kinematic viscosity, CV, density, flash and fire point get improved in case of biodiesel. The calorific value of methyl ester is lower than that of diesel because of oxygen content. The flash and fire point temperature of biodiesel is higher than the pure diesel fuel this is beneficial by safety considerations which can be stored and transported without any risk.

Table 2.1 Fuel properties

\begin{tabular}{|l|l|l|}
\hline Properties & Diesel fuel & COME \\
\hline $\begin{array}{l}\text { Kinematic viscosity at } 40^{\circ} \\
\mathrm{C}(\mathrm{cSt})\end{array}$ & 4.1 & 16.2 \\
\hline Calorific value(KJ/Kg) & 42000 & 38000 \\
\hline
\end{tabular}




\begin{tabular}{|l|l|l|}
\hline Density $(\mathrm{Kg} / \mathrm{m} 3)$ & 0.831 & 0.920 \\
\hline Flash point $\left({ }^{\circ} \mathrm{C}\right)$ & 51 & 175 \\
\hline Fire point $\left({ }^{\circ} \mathrm{C}\right)$ & 57 & 185 \\
\hline
\end{tabular}

\section{EXPERIMENTATION}

\subsection{Engine Components}

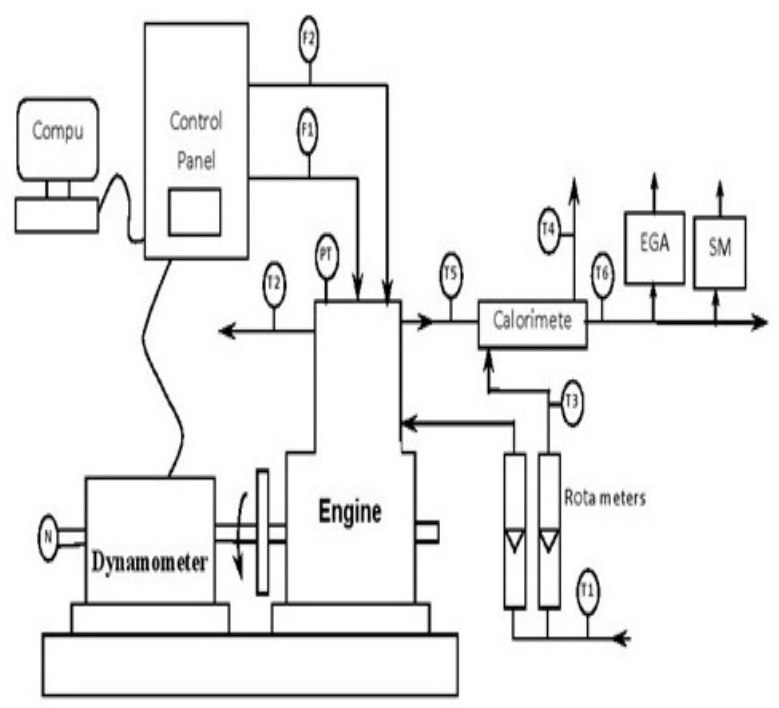

Figure.3.1 experimental set up

Figure.3.1shows the line diagram or various components of experimental set up. The important components of the system are:

1. The engine

2. Dynamometer

Table 3.1 gives the notations

\begin{tabular}{|l|l|}
\hline PT & Pressure transducer \\
\hline N & Rotary encoder \\
\hline Wt & Weight \\
\hline F1 & Fuel flow \\
\hline F2 & Air flow \\
\hline F3 & Jacket water flow \\
\hline F4 & Calorimeter water flow \\
\hline T1 & Jacket water inlet temperature \\
\hline T2 & Jacket water outlet temperature \\
\hline T3 & Calorimeter water inlet temperature $=$ T1 \\
\hline T4 & Calorimeter water outlet temperature \\
\hline T5 & Exhaust gas to calorimeter temperature \\
\hline T6 & $\begin{array}{l}\text { Exhaust gas from calorimeter } \\
\text { temperature }\end{array}$ \\
\hline
\end{tabular}

Table 3.2 Engine specifications

\begin{tabular}{|ll|}
\hline $\begin{array}{l}\text { Manufacturer } \\
\text { India } \\
\text { Model } \\
\text { aspirated }\end{array}$ & \multicolumn{1}{c}{ Kirloskar oil engines Ltd, } \\
Engine & \multicolumn{1}{c}{ TV-SR, naturally } \\
Bore/stroke & Single cylinder, DI \\
C.R. & $87.5 \mathrm{~mm} / 110 \mathrm{~mm}$ \\
speed & $16.5: 1$ \\
Rated power & $1500 \mathrm{r} / \mathrm{min}$, constant \\
Working cycle & $5.2 \mathrm{kw}$ \\
Injection pressure & four stroke \\
Type of sensor & 200bar/23 def TDC \\
Response time & 4 micro electric \\
Crank angle sensor & 1-degree crank angle \\
Resolution of $1 \mathrm{deg}$ & 360 deg with a resolution \\
of 1deg & \\
\end{tabular}

\section{RESULT AND DISCUSSIONS}

4.1 Comparative Analysis of Performance And Combustion Characteristics of Castor Biodiesel Blends And Diesel on Normal Engine And Low Heat Rejection Engine:

4.1.1 Variation of Brake Thermal Efficiency with Brake Power

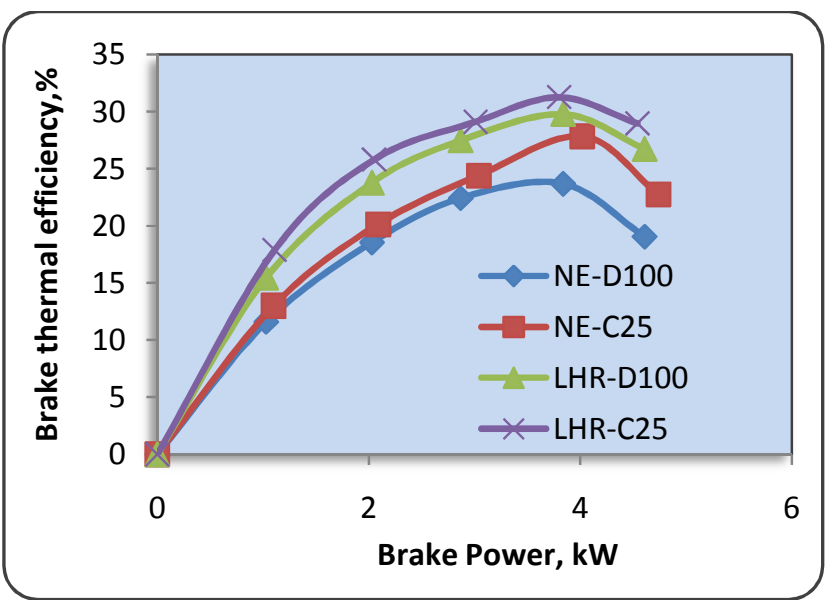

Figure 4.1 Variation of brake thermal efficiency with brake power

The variation of the brake thermal efficiency with load for diesel and come blends are shown in figure 4.1,we can observe that C25 with LHR has higher brake thermal efficiency than normal engine D100 this is because of 
increased combustion rate which provides complete burning of fuel and due to low heat rejection. The thermal efficiency of C25 is lower than diesel due to large difference in viscosity specific gravity and volatility.

\subsubsection{Variation of Mechanical Efficiency with Brake}

\section{Power}

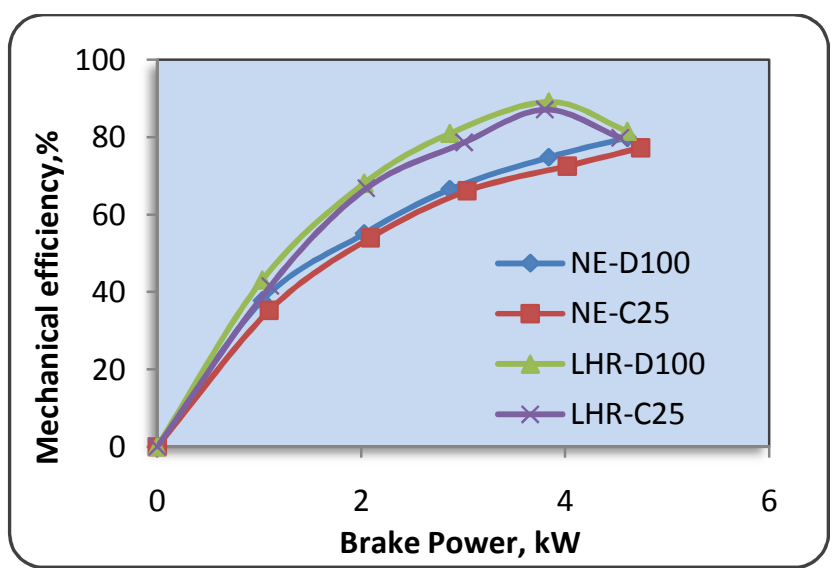

Figure 4.2 Variation of mechanical efficiency with brake power

The variation of the mechanical efficiency with load for diesel and COME blends are shown in fig.4.2. It is observed that mechanical efficiency increases the load. C25 and D100 are almost same so C25 shows better result as compared to other blends.

\subsubsection{Variation of Specific Fuel Consumption with}

\section{Brake Power}

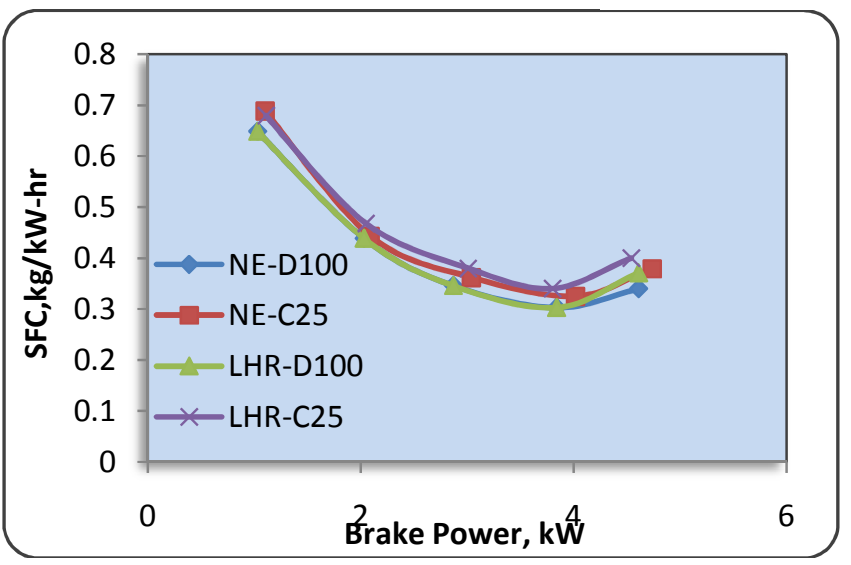

Figure 4.3 Variation of specific fuel consumption with brake power

The variation of the specific fuel consumption with load for diesel and COME blends are shown in figure 4.3. A decrease in SFC with increase in load was observed. The SFC of diesel engine depends on the relationship among volumetric efficiency fuel injection, fuel density viscosity and lower heating value. More biodiesel and its blends are needed to produce the same amount of energy due to its lower heating value its comparison with diesel fuel. The SFC increased with the increasing proportion of biodiesel in the blend.

\subsubsection{Variation of Indicated Mean Effective Pressure} with Brake Power

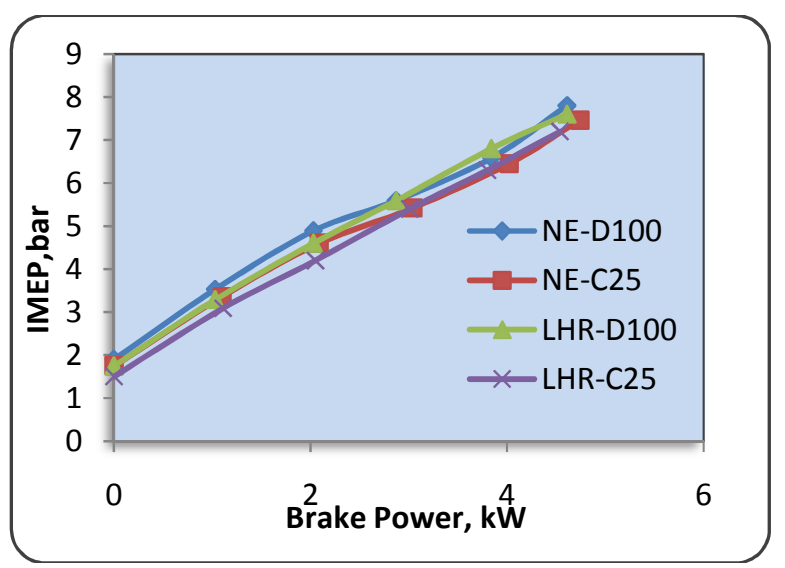

Figure 4.4 Variation of indicated mean effective pressure with brake power

The variation of the mean indicated pressure with load for diesel and COME blends are shown in figure 4.4. Indicated mean effective pressure is low for COME compared to diesel this is because of volatility and caloric value of COME. By using thermal barrier coating there is slight increase in indicated mean effective pressure as compared to normal engine. Here we can observe that as the load increases the mean pressure of an engine increases.

\subsubsection{Variation of Air-Fuel Ratio with Brake Power}

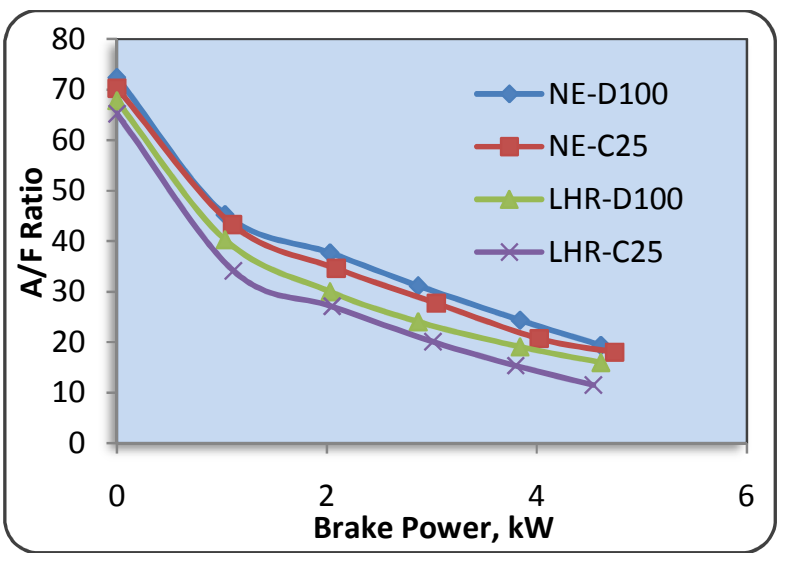

Figure 4.5 Variation of air-fuel ratio with brake power 
The variation of the air fuel ratio with load for diesel and COME blends are shown in figure 4.5. Fuel consumption is for COME blends compared to diesel hence air fuel ratio decreases with increase in load because air fuel mixing process is affected by the difficulty in atomisation of the biodiesel due to its higher viscosity.

\subsubsection{Variation of Exhaust Gas Temperature with}

\section{Brake Power}

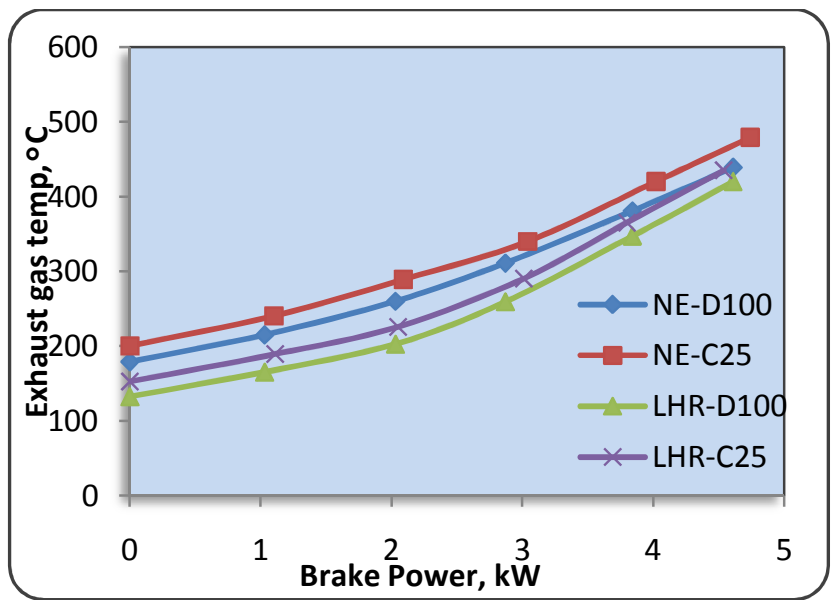

Figure4.6 Variation of exhaust gas temperature with brake power

The variation of the exhaust gas temperature with load for diesel and COME blends are shown in figure 4.6. When Bio fuel concentration increases the exhaust temperature increase. The same also when load increases the exhaust temperature increases.

\subsubsection{Variation of volumetric efficiency with brake}

\section{power}

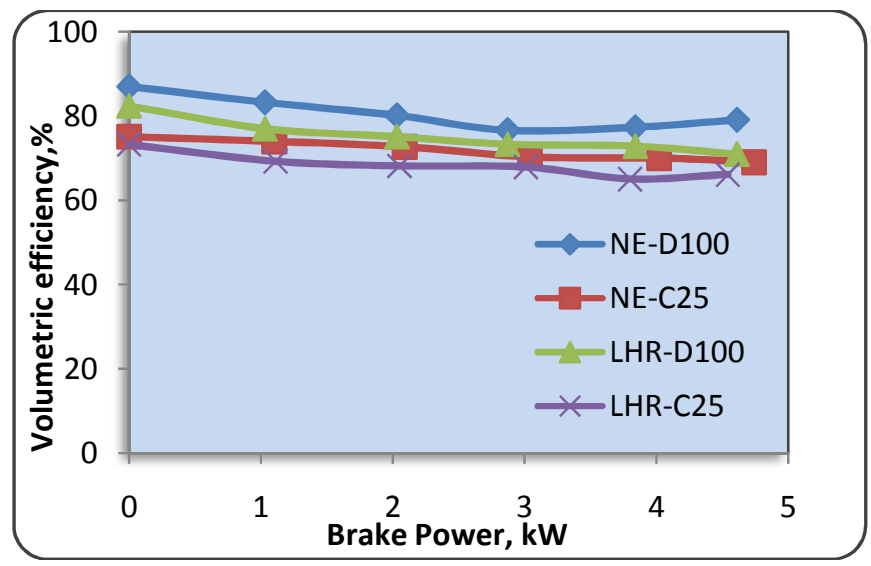

Figure 4.7 Variation of volumetric efficiency with brake power
The variation of the volumetric efficiency with load for diesel and COME blends are shown in figure 4.7. From the above graph we concluded that there is no much difference in volumetric efficiency with each load. But volumetric efficiency for NE-D100 is slightly higher than the LHR-D100, because there is slight decrease in volume of the LHR engine due to coating. And efficiency for NE-C25 and LHR-C25 are almost similar.

\subsubsection{Variation of Crank Angle V/S Cylinder}

\section{Pressure}

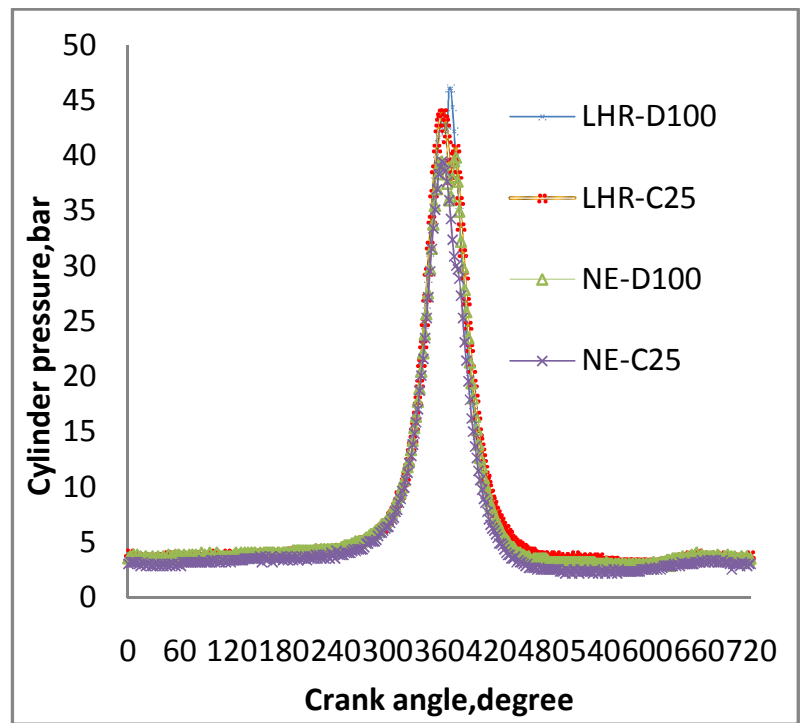

Figure 4.8 Variation of crank angle v/s cylinder pressure

In a CI engine the cylinder pressure is depends on the fuelburning rate during the premixed burning phase, which in turn leads better combustion and heat release. Figure 4.8, shows the typical variation of cylinder pressure with respect to crank angle. The cylinder pressure in the case of biodiesel fueled LHR engine is about $4.7 \%$ lesser than the diesel fueled LHR engine and higher by about $1.64 \%$ and $12.22 \%$ than conventional engine fueled with diesel and biodiesel. This reduction in the in cylinder pressure may be due to lower calorific value and slower combustion rates associated with biodiesel fueled LHR engine.

However the cylinder pressure is relatively higher than the diesel engine fueled with diesel and biodiesel. It is noted that the maximum pressure obtained for LHR engine fueled with biodiesel was closer with TDC around 2 degree crank angle than LHR engine fueled with diesel. The fuel-burning rate in the early stage of combustion is higher in the case of biodiesel than the diesel fuel, which bring the peak pressure more closely to TDC. 


\subsubsection{Variation of Crank Angle V/S Heat Release}

\section{Rate}

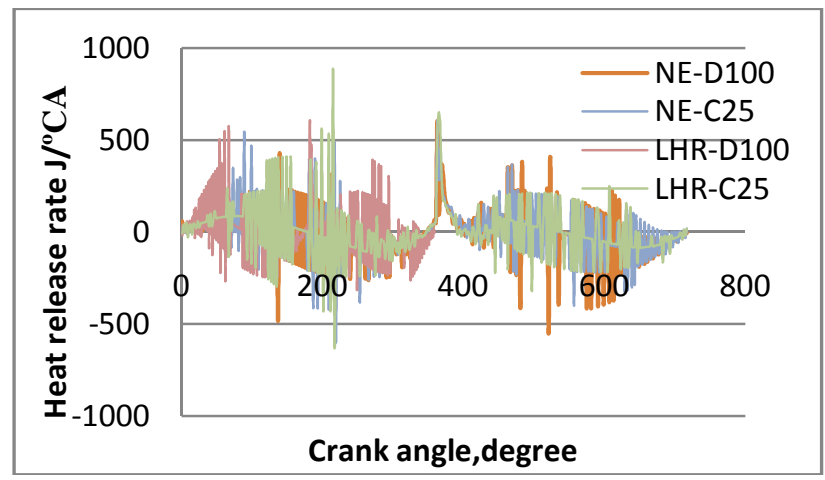

Figure 4.9 Variation of crank angle v/s heat release rate

Figure 4.9 shows the effect of crank angle on heat release rate at maximum load for C25 and D100 for both NE engine and LHR engine. Castor biodiesel shows lower heat release rate during premixed burning phase compared to diesel. The high viscosity and poor volatility of NE-D100 result in poor atomization and fuel air mixing rates. Heat release rate is more in LHR-C25 compared to LHR-D100 and heat release rate in NE-D100 and NE-C25 are almost similar. Hence, more burning occurs in the diffusion phase, leads to a faster heat release (combustion), improved remixed combustion.

\section{CONCLUSIONS}

The following conclusions were drawn from these investigations carried out on normal engine and LHR engine for different loads:

- Using insulation to reduce the heat loss to the cooling system of the engine causes the cylinder walls to become hotter and increases exhaust gas energy.

- Thermal efficiency is not improved to the same extent that heat rejection is reduced by combustion chamber insulation.

- High temperatures on the combustion chamber wall surface due to insulation cause a drop in volumetric efficiency although increased boost pressure from the turbocharger can be used to overcome this problem.

- The detail study of performance and combustion characteristics of castor biodiesel and its blends on normal engine we can observe that $25 \%$ blend of castor biodiesel in diesel fuel has almost same mechanical efficiency, same specific fuel consumption and same indicated thermal efficiency.

- We can also see that there is slight increase in brake thermal efficiency which is a positive sign with this blend. In case of peak pressure we can see that there is almost same pressure as that of diesel fuel.

- So we can conclude that without any modification in engine we can save diesel fuel for certain extent without any compromise with standard performance and combustion characteristics and in future castor biodiesel can be a best alternative fuel which can replace the diesel.

- There is increase in parameters like brake thermal efficiency, mechanical efficiency and brake mean effective pressure and there is decrease in specific fuel consumption, volumetric efficiency and fuel consumption which can be observed in comparative graph. There is also increase in peak pressure which higher than that of biodiesel with normal engine.

- Castor biodiesel shows lower heat release rate during premixed burning phase compared to diesel. The high viscosity and poor volatility of NE-D100 result in poor atomization and fuel air mixing rates. Heat release rate is more in LHR-C25 compared to LHR-D100 and heat release rate in NE-D100 and NE-C25 are almost similar.

- We can conclude that the C25 with LHR shows same graphs as compared to D100 this blend is best suitable for an engine.

\section{REFERENCES}

[1]. Ilker Turgut Yilmal, Metin Gumus, Mehmet Akcay, Thermal Barrier Coatings For diesel Engines. International scientific conference 19-20 November 2010, Gabravo Turkey [2]. Www.energyrevolution.co.za/biodiesel/what is biodiesel

[3]. Hemant Y. Shrirame, N. L. Panwar, B. R. Bamniya Bio Diesel from Castor Oil - A Green Energy Option, Low Carbon Economy, 2011, 2, 1-6 doi:10.4236/lce.2011.21001 Published Online March 2011 (http://www.SciRP.org/journal/lce) Copyright

[4]. CH.S Naga Prasad, Synopsis Doctor of philosophy at JNTUH College of Engineering Hyderabad. Jan-2010

[5].www.Energyrevolution.Co.Za/Biodiesel/Advantages/ disadvantages

[6]. Sri Harshatirumala, A.V.Rohit, Sivakrishna.M, Sudipta Saha. Synthesis Of Neem Biodiesel.

[7]. International Journal Of Advanced Engineering Technology E-Issn 0976-3945.

[8]. B. Rajendra Prasad1, P. Tamil Porai2, Mohd. F. Shabir1 Two-Zone Modeling Of Diesel / Biodiesel Blended Fuel Operated Ceramic Coated Direct Injection Diesel Engine International Journal Of Energy And Environment Volume 1, Issue 6, 2010 Pp.1039-1056

[9]. Murthy P.V.K , Murali Krishna M.V.S , Sitarama Raju A , Vara Prasad C.M. Srinivasulu N.V. Performance Evaluation Of Low Heat Rejection Diesel Engine With Pure Diesel. International Journal Of Applied Engineering Research, Dindigul Volume 1, No 3, 2010

[10]. A. Siva Kumar, D. Maheswar, K. Vijaya Kumar Reddy, "Comparison of performance parameters by using jatropha and fish oil as biodiesel", Proc of the International Conf. \& XX National Conf. on I.C. Engines and Combustion, pp. 235239, (2007) 